\title{
Reflections on Interpretivist Teaching with Positivist Students
}

\author{
David A Banks \\ University of South Australia, Australia
}

david.banks@unisa.edu.au

\begin{abstract}
This paper reflects upon the teaching of two final year undergraduate subjects, Information Systems Policy and E Commerce, in a Management Information Systems degree program that is located in a School of Accounting and Information Systems. Both of the subjects were taught from an 'interpretive' standpoint, an approach that some students found to be challenging given that they were more familiar with the highly structured and positivist approach used in most of their previous subjects. Student feedback gained from informal conversations with the lecturer, an electronic meeting and through paper questionnaires as part of the normal formal evaluation process, is used to explore some of their reactions to a 'soft' approach and to provide a basis for consideration of future delivery patterns for the subjects.
\end{abstract}

Key words: education, MIS, interpretivism, positivism, reflection

\section{Introduction}

The two subjects examined here, Information Systems Policy (ISP) and Electronic Commerce (EC), are both final year undergraduate subjects in an MIS degree located in a school of accounting and information systems. Each subject typically has ninety students for each subject, comprising roughly equal numbers of full time and part time students. ISP and EC are usually the last subjects that students take prior to completing the degree, with ISP originally conceived as a 'capstone' subject. The EC subject was developed to provide a more theoretical view of the subject to complement a more hands-on web development subject that is also in the degree program.

The motivation for this reflection was the very mixed feedback, some very positive, some very negative, with a significant number of students unsure about the experience of studying these two subjects. The negative responses tended to be strongly worded and it was mainly these that triggered a full review of the content and process by the mem-

Material published as part of this proceedings, either on-line or in print, is copyrighted by the author with permission granted to the publisher of Informing Science for this printing. Permission to make digital or paper copy of part or all of these works for personal or classroom use is granted without fee provided that the copies are not made or distributed for profit or commercial advantage AND that copies 1) bear this notice in full and 2) give the full citation on the first page. It is permissible to abstract these works so long as credit is given. To copy in all other cases or to republish or to post on a server or to redistribute to lists requires specific permission from the author. ber of staff responsible. The feedback that has informed the reflective process has been drawn verbatim from formal course evaluation questionnaires for both subjects, and also from an electronic meeting session for ISP, plus feedback received informally from students studying both subjects. Both subjects were taught with the same guiding educational philosophy and also from an interpretivist viewpoint and both subjects received similar reactions from the students

\section{Teaching 'drivers'}

In common with many subjects in the information systems area the subjects of ISP and EC can be viewed from a number of perspectives in both 'hard' and 'soft' domains. Although there is a tendency for students to concentrate upon and highly value the hard, or technical, views of the subjects, it can be argued that both subjects have strong human elements that must be taken into account for a broader understanding to be developed. In the case of ISP it is clearly important to appreciate the current and emergent technological developments, as it is these that lead to modifications to existing policies or to demands for new ones. However, equally important is an understanding that the development of policies that influence, for example, freedom of access to internet from business premises, use and monitoring of email and so on, is framed by human beings with personal and political value systems rather than directly by the technology itself. Checkland and Scholes (1998, pA43) suggest that "A systems thinker would know 
that the process of policy creation and policy content are entirely complementary, the process itself conditioning what might emerge as content. Both need to be thought about together; but this is not yet a familiar concept". Sauer (1994, p331) notes that "The first recommendation for action was for practitioners to accept the political nature of information systems and act accordingly. For some this comes naturally, for others it is anathema".

Similarly, in the case of EC there is an obvious need for students to develop practical skills in producing web pages, but equally they do need to be aware that appreciation of such issues as new modes of marketing, security and trust, management of change etc are significant in the development of effective web services. Flood (1995, p5) comments that "Today, managers have to cope with a rapidly developing technology for the workplace, escalating amounts of management information moving around at great speed, rising consumer awareness, growing expectations of employees, as well as having to handle corporate culture, office politics and the interests of suppliers, pressure groups and a concerned public." He goes on to say that organisations have become "fuzzy things with problems that are hard to understand" and that "Methods that are able to stimulate and provoke creative and perceptive thought about these matters are needed".

The changing nature of the modern business environment may lead to the demand for new workforce characteristics, including the development of critical and creative thinking skills. Students clearly need to be equipped for a world where specific practical skills are of initial importance in entry to employment and these skills can be taught from a positivist and reductionist point of view. However, it is this writers belief that these basic technological skills will need to be supplemented by flexible and critical thinking within the context of the complexity and dynamics of a changing business and technology environment and that only a 'softer' approach will achieve this end.

The Graduate Qualities statement of the University of South Australia, developed in consultation with the local business community, recognises the need for providing students with both 'hard' and 'soft' skills and knowledge. For example the 'hard' views can be encapsulated by the Graduate Quality statement that graduates will "Operate effectively with and upon a body of knowledge of sufficient depth to begin professional practice". The 'softer' issues are embedded in the statements that the students should be "prepared for lifelong learning in pursuit of personal development and excellence in professional practice" and be "an effective problem solver capable of applying logical, critical and creative thinking to a range of problems".
With the foregoing issues and Graduate Qualities in mind, and recognising that many other subjects in the degree addressed the 'hard' issues, a teaching strategy was adopted for both subjects that was strongly grounded in the interpretivist, or 'soft', side of the IS field. Technology was relegated to the background and human and organisational aspects brought to the foreground with the notion of 'reality as a social construct' as a key theme. Both subjects commenced with an explanation to the students of where the teaching was grounded and that this would be very much a case of both 'lecturer' and student exploring (or researching) the subject rather than a more typical teach/remember/test model. The importance and validity of multiple views was stressed, provided, of course, that each view could be adequately supported by credible evidence. This was developed into ideas of complexity, eclecticism, richness and change as drivers lying behind the mode of exploration for the subjects.

It was anticipated that such an approach could raise some difficulties for students who appear to have been exposed to a more positivist approach in previous subjects. Both positivist and interpretivist approaches are, of course, equally valid in the field of information systems, Checkland and Holwell (1998, p62) commenting that the two major strands on thinking, 'hard' and 'soft' in the IS field yield very different bodies of knowledge and research approaches'. They characterise the 'hard', or positivist, approach as being founded on the idea that 'organisations are goal-seeking entities and that the role of information is to aid decision making'. This is a fairly typical underlying theme in a number of subjects in the MIS degree. The 'soft', or interpretive, approaches views 'organisations as relationship-managing entities ... [where] information is relevant to sense making ... they will explore how sense making occurs in particular circumstances'. Despite the potential difficulties it was felt that a different view would 'round' the students appreciation of the field and offer a beneficial experience.

To support the subjective nature of the interpretivist approach the underlying teaching philosophy was broadly Socratic in nature, working through the stages described by Plato:

"First, the stage called 'opinion', in which the individual is unable to give valid reasons for his knowledge or supposed knowledge

Second, the destructive or analytic stage, in which the individual is brought to realise that he does not know what he assumed he knew, and which leads to contradiction and a mental condition of doubt or perplexity 


\section{Reflections on Interpretivist Teaching with Positivist Students}

Third, a synthetic stage for the results of which Plato would reserve the term 'knowledge'. When this last stage is attained, the individual's experience is critically reconstructed and he can justify his beliefs by giving the reasons for them" (Rusk, 1957, p5)

Many students appear come to subjects with a preconceived idea ('opinion') of what the subject is about, generated largely by a positivistic view of the world, eg that there is a simple, obvious and causally connected set of rules that apply to any subject and once these are understood all aspects of the world can be explained and managed. The task in these subjects was to challenge those presuppositions (the analytic stage) and then to leave the students in a position where they could move towards supporting their understanding of the subject in a justifiable manner. This requires that students are led towards the position where they are able to identify a range of possible interpretations for a given situation, and to then try to reach a balanced conclusion through argumentation (synthesis) supported by the use of credible evidence. Students also typically bring with them an expectation of careers that fit with a fairly traditional, ordered and relatively static world and it can be argued that education should provide students with the broad skills and attitudes required for an increasingly dynamic business environment. The challenging of positivist views and of a traditional working environment are likely to be difficult experiences for students, but one of the fundamental roles of education should be to encourage change and new thinking rather than simply support the status quo. Spencer (1851, in Rusk, p290) comments that:

'(On the other hand), education ... is closely associated with change - is its pioneer - is the never sleeping agent of revolution - is always fitting men for higher things, and unfitting them for things as they are. Therefore, between constitutions whose very existence depends on man continuing what he is, and true education, which is one of the instruments for making him something other than he is, there must always be enmity'.

In summary, the approach taken to the teaching of these two subjects was firmly grounded in the interpretivist region of the information systems field and encouraged the learner to place some existing positivist suppositions to one side and to consider ways in which human beings interact with a dynamic and possibly rapidly changing business environment that is socio-technical in nature. It also supports the view that education is a transformational process that produces autonomous individuals rather than producing students who conform to employer direction (Bentley, Lowry and Sandy, 1999, p66). The delivery pattern comprised lectures, tutorials (mainly drop-in), individual and group work, and debate sessions. Further details of the structure and teaching approach for the ISP subject can be found in Banks, 2000.

Student feedback, gained from formal Course Evaluation Questionnaires, informal contact with students and from an electronic meeting, provided a range of responses, from very positive through to highly critical with many comments common to both subjects reviewed here. This, in itself, was not of great concern as there is considerable literature that reveals similar students reaction, Falk (1966) for example reporting that students regarded a series of lectures as:

"Made a fascinating period of history flat"

"Congratulations on an exceedingly workmanlike job of teaching as opposed to purely lecturing"

"Gives students the impression that they are back in the schoolroom. By this I mean over-simplification, over classification"

"These lectures were the best I've had this year"

A similar range of comments was obtained for ISP and EC and the remainder of this paper explores some of the feedback in the context of the 'soft' approach used within a degree that could be characterized as being mainly 'hard' in content and process

\section{"Over-intellectualisation" and real world applicability}

The most negative comment, and the one that triggered the reflective process, in the feedback from ISP students was; "Depends if I pass or not - but otherwise it was directionless and pointless, didn't learn much just did the work, same as ecommerce. David tried to over-intellectualise an essentially unintellectual degree". Fortunately this negative comment was balanced by some very positive comments, including:

"The lecturer made it interesting, he brought up new areas of thinking and encouraged us to explore these. Even though many are philosophical they are very relevant many areas of life and living"

"By the end I had learnt new knowledge, acquired new skills and questioned beliefs; all at a level expected of third years". 
"I came with an initial view of E Commerce that was very naïve - now I see how broad and interesting this is I want to study much further".

"The only subject other than ISP that made you think and properly research"

The "over intellectualisation" indicated in the comment above was, however, echoed to a lesser degree in a number of other comments who felt that the subject was "very academic, philosophical, theoretical, unexpected approach, unconventional" and that "the lecturer discusses topics in an academic manner, which can be confusing for undergrads to grasp". Other related comments included "He tried his best, he is just a bit advanced for us" and "The lecturer was very good in explaining things especially from academic point of view". If one interprets "academic" as "scholarly as opposed to technical or practical" (Oxford Reference Dictionary) then students who have a positivist view of the world that demands overt skills in programming, single solutions and requires their heads 'to be filled with knowledge by the lecturer' could be expected to feel somewhat off balance. Interestingly, one student did pick up on my intentions when they commented that "I felt that the lecturer had a 'real world' perspective and wanted to merge 'academia' with the real world." This was from a Swedish student studying for a year in South Australia and may suggest that the lecturer still has a European rather than Australian approach to education.

The views on the usefulness of the subject to "the real world' were equally as polarised as for other aspects of the subjects, typified by those who felt that there was $a$ "Good business context" and "useful working on relevant material - good for employment prospects - using up to date resources allowing choice of essay material - could pursue area of personal interest", through to "The subject didn't really provide anything that would be useful in industry. The subject was unstructured", and "Move emphasis from philosophy/ethics to more practical emphasis on EC". One ISP student commented that "I came to the subject wanting to know how to write policies, not all this soft stuff about vision, mission, politics, ethics and so on. I still don't feel that I know how to write policies". This was echoed in EC by a comment that "I came into this expecting a more technical hands on approach. I would have liked to build a fictional e-commerce site that would have been far more rewarding”.

Many of the comments above suggest that some students have still not understood that there are multiple viewpoints and these should be examined before being simply discarded as not providing a basic 'skill' that supports em- ployment prospects. If the purpose of education were simply to fit students for the needs of employers then this would be a valid argument. However, the approach taken in these subjects was more oriented to the broader graduate qualities that form a key platform for the university than to specific skill sets that could probably be better served in a TAFE environment. The tension between broad education and specific skill sets clearly needs to be carefully considered in future developments of these subjects.

\section{Influence of Previous MIS subjects}

A number of comments suggested that subjects prior to ISP and EC were perceived by students as being constructed on a more highly structured basis and positivistic:

"There seemed a lack of prescriptive direction that is often given in other subjects"

"I have not had another subject like this that has not just handed me the answers in lecture notes"

"It was quite clear that this is not a spoon-fed subject (unfortunately?)"

"Students [studying ISP and EC] are expected to be students and actually do some research (a novelty compared to some other subjects)"'.

The MIS teaching team is aware of some of the tensions between subject delivery styles and is obviously keen to address the issues. It will require considerable collegiate effort to consider what the most appropriate styles are for the MIS degree and any changes to the learning environment may represent a cultural change that could take several years to implement. Ideally there will be a mix of positivistic and interpretivist teaching and learning to suit the perceived needs of students in initial and longer term careers.

The themes of previous expectations of high levels of guidance, single rather than multiple answers, and overt structure were frequently commented on by students, with many comments relating to the 'lack of structure, guidance and direction' for ISP and EC in comparison with many previous subjects. The lecturers efforts to offer the broadest possible views of the various topics in both ISP and EC and to discuss the issues with students in small groups or one to one to provide focus seems to have caused concerns for some students, eg "Explanations were in the form of multiple definitions, I understand the desire to avoid black and white answers but more cut and dry would have been better" and "When seeing lecturer, many different points put 


\section{Reflections on Interpretivist Teaching with Positivist Students}

across, hence confused students". Some students found it hard to understand that as the lecturer read more and examined the subject to greater depth his own views changed and this sometimes led to minor re-interpretations of previous weeks ideas. Other students found the ability to engage the member of staff in debate and possibly influence his thinking to be stimulating. It may be that the expectation that students would engage with the subject and read more broadly is an unreasonable assumption to make at undergraduate level.

\section{Textbook and tutorial support}

One approach to reducing the complexity of views is, of course, to adopt a single or small number of texts for the subject. This approach was deliberately rejected, the students being encouraged instead to use a variety of sources including books, business and academic journals, conference papers and Internet sources to help them form a balanced view. Many students, however, continued to pursue the idea that there was one single answer to any issue and that, as for previous subjects, a textbook would provide this for them. One student commented that EC was a "Very broad subject, no given pages to read and can be a bit hard if you are not used to that system", another offering the stronger view that the lecturer should "Find a textbook and teach a chapter per week- then have an exam, - This not rocket science". Another commented that "Even if a subject is changing too fast for literature to keep up, I would recommend readings that give the basic facts. Fundamental things will always be the same." In a sense this may be true, but one could argue that for EC in particular there is no single book that 'gives the basic facts' in anything other than the technical domain. Even then one would be tempted to argue that there is no single 'best' technical solution within the context of a business environment possibly characterised by step function rather than evolutionary change, and particularly if one adopts a socio-technical standpoint.

Those students who had studied both subjects found that whichever subject they studied first prepared them for the following one, in other words they were able to adapt to the approach. It seems likely that the problems of perceived lack of structure and guidance were very much in reaction to their previous MIS subject experiences rather than to the EC/ISP approach as such. Typical comments included:

"Doing EC helped me know what was expected in ISP as the teaching method was the same"

"Having David for Electronic Commerce last semester made me familiar with his teaching methods"
"I enjoyed ISP and it was good to have the same challenge in E Commerce"

"Having done E-Commerce last semester certainly helped with understanding the lecture formats, backed up by the website notes".

"After doing electronic commerce the important aspect of self discovery had been beaten into us"

One major problem with the delivery pattern was that of the use of a 'drop-in' support approach, in which students were able to access the member of staff on an informal basis during a nominated period). Many students not familiar with this flexibility of support found it difficult to manage their own time and found the lack of forced contact to be a negative rather than positive approach:

"It doesn't have compulsory tutorials which allow us to ask him questions individually”.

"If student was not motivated, then would not get any encouragement, because would not see lecturer"

"I found the non-structure of the tutorials made it easy not to attend, and therefore the less contact resulted in less motivation".

"I didn't feel motivated. I can't pin it down to anything to do with the subject however - it may have been because of my attitude and the fact that I need to be pushed (and not given much freedom) before I do my best work".

"Without the tutorials to provide guidance it was difficult to know exactly where I was at. I felt isolated from the subject, other students, lecturer, tutor and there were very few guidelines".

"We were left to do our own thing - Ifelt as if we didn't have help if we needed it"

On the other hand, those students who were able to adopt a flexible and self-motivated approach seem to have enjoyed the experience and felt that it was useful:

New approach to teaching a subject not encountered before. Very open - emphasis for motivation on student takes getting used to but at $3^{\text {rd }}$ year it helps student 'grow up'.

The motivation from the lecturer to take charge of your own learning and not rely on a set structure was good. 
This subject did not baby-sit students and give them the answers, but encouraged self learning and group learning.

I enjoyed the lack of formal structure in the course and found the philosophical aspects provoked more thought outside the immediate scope of the lectures

It was certainly different to the more traditional subjects; it promoted self-learning which I think was important in the overall context

The informal 'surgery' approach works well for students who are self motivated and want to self-pace their learning but it would appear that there are large numbers of students who are unable, or unwilling, to organise their own learning. Those students who used the time well were able to work through a 'stepwise refinement' of their thinking and so produce high quality work. Those who did not make use of the time tended to hand in poorly structured report-style work that tended to be descriptive rather than analytic. The idea of self managed learning needs to be more strongly introduced in the early years of the MIS degree to help alleviate this problem.

\section{Student views of the subjects 'interest value'}

Students do not seem to have brought many expectations about the nature and content of ISP with them. The feedback indicated that the subject material was generally felt to be "very hard to make interesting", "rather dry" and "wasn't very inspiring, which didn't really motivate me from the beginning". Other students commented that "I didn't think ISP was an interesting subject. I mean Information Systems Policy seems a little boring, but it turned out ok I guess" and "The subject is such a dry field in the first instance, so I take my hat off to anyone who wishes to make it interesting". This subject explored the ways in which practical policies for a 'virtual' university could be developed, driven by the vision, mission and structure of the organisation. Possibly the choice of another type of organisation would improve the interest value of the subject. The use of a debate session in this subject was well received and the level of work was generally very good.

Students entering EC, on the other hand, did start with some expectations, mainly in the direction of the technical issues of building web sites. The unexpected approach examining, for example, whether or not an organisation should consider taking the web direction in the first instance, challenges to existing marketing wisdom, areas of opportunity, creativity, the value of semiotics, 'soft' systems approaches to systems development etc did initially disturbed some students. However, the feedback suggests that the eclectic approach seems to have been useful for a reasonable number of students:

"Gained a different viewpoint and perspective on the subject”.

"Looked at e-commerce from a different angle".

"The exposure to a variety of writings on the subject and the opportunity to examine different viewpoints opened some possible future areas to explore".

"Interesting - some new views and ideas to explore - not technical"

"By generating interest in topics, introduced questions that made me ponder"

"It provided me with an insight into IS that was not just based on IT but on a wide subject area"

"I found that unlike other IS subjects, the lecturer involved other areas such as philosophy to explain the way the world works"

"The lecture contained relevant, but sometimes obscure examples (is that wall yellow?)"

In contrast, a number of students felt that the subject was tackled from too broad or philosophical a point of view, commenting that "the lecturer would go off in tangents", "somewhat wordy" and "Too philosophical - not my style of learning"

Once again is difficult to find the balance between the introduction of broad concepts that should prepare students for the exciting 'e-world' that may prevail and the more pragmatic skills that many students feel they need. Some modification to the content and delivery style should achieve a reasonable compromise. Several students suggested that the use of a case study to provide focus would be beneficial and this approach is being considered, with the use of debate as for ISP a possible mechanism for development. This will require that more formal tutorials are held which, in turn, will satisfy those students who feel unable to manage their own learning.

\section{General comments}

In general terms the subjects seem to have met their intended learning outcomes of providing the students with broad views of the two areas of ISP and EC , introducing 


\section{Reflections on Interpretivist Teaching with Positivist Students}

them to a relatively 'soft' interpretivist approach and promoting self-management of learning. Broad comments from students included:

"The subject exposed me to subjects within info systems I would not normally consider"

"It was worthwhile; the topic is contemporary and the discussion is thought-provoking".

"Enjoyed the teaching methods and assessments was different to other subjects"

"It developed skills that other subjects in the course don't"

"Interesting to me because I have some shared interests, but perhaps the lectures were not interesting to nerds"

"We were encouraged to think and come up with our own ideas".

"Developed my analytical skills, developed my research skills".

One particularly interesting comment was that "This was a quality ARTS subject, I felt that it was not oriented towards the business degree enough and as such did not constitute high quality". I am not sure what the student was thinking (this was drawn from the electronic feedback meeting which provided anonymity for participants) but perhaps it reflects the arts/sciences or positivism/interpretivism debate. The subject material was clearly located in the business domain rather than in the computer science domain and as such fits comfortably within the scope of an MIS degree.

Structural issues were strongly present in both subjects, typically expressed as "Provide more direction, guidancewhat is expected of students. I realise that is difficult given the scope of the subject but it would help us measurably". Students offered useful suggestions that indicated an attempt to seek a compromise between their needs for this more overt structure and guidance and the recognition of the potential value of a flexible system:

'Perhaps a formal structure on the basics of e-commerce for the first few weeks then a more open learning environment as it already is'.

'Maybe just a little bit of structure - lecture weeks outline at start etc. Some tutorial work so that all feel we known how we are going (lecturer \& students)'.
The problems faced by students when the direction is not sufficiently clear are probably best expressed in the two comments below, the first from EC and the second from ISP:

'Lectures gave a broad outline of what was expected, but never quite sure what it should look like when finished.'

'The lecture provides a foundation to go away and build on - a problem being that I often wasn't sure if I was building a sky scraper or a house...'

\section{Conclusion}

The lack of 'direction' would seem to have been to root cause of many of the problems and is the main area that needs to be worked on here. It is evident that it is difficult for students used to subjects where there appear to be clearcut and unambiguous answers (ie positivist in nature) to cope with a softer, interpretivist approach. One could argue that the students who did not gain, in their eyes, skills or knowledge that directly supported their career aspirations have been unfairly treated and that positivism is the most appropriate approach in the MIS domain. Indeed, many small to medium enterprises (SME), of which South Australia has many, would appear to be seeking practical abilities in programming, analysis, database development and so on. The larger organisations, on the other hand, appear to want flexible and critical thinkers who can cope with change and challenge. It is this writers view that ideally a students educational path should expose them to the widest possible range of learning experiences so that they have the freedom to choose a corporate, SME or self employed career in information systems. Finding a way to achieve this and help students see the value of both positivism and interpretivism may be a challenging task. It may be more sensible to bring ISP and EC into line with the rest of the MIS degree subjects, that is to make it strongly positivist, and so avoid any discontinuities between subjects, than to embark upon a long and difficult culture change possibly driven by a minority view of the IS domain.

The reflection in this paper was sparked essentially by one students strong criticism that made the lecturer question their basis for facilitating learning in a particular way and of the appropriateness of such an intrerpretivist, rather than positivist, approach for undergraduate students. The reflective process is still ongoing and continues to raise difficult and challenging issues, but I was heartened, and amused, by the comments below:

"I could tell my employer that there is no such things as facts" 
David A Banks

"Thinking outside the square is GREAT!!!!"

"There is not always a right answer,!!!"

"Good to hear that there is no right answer-but that could make my Accounting assignment a bit more difficult!!”

\section{References}

Banks, D A, (2000), Teaching Information Systems Policy: Electronic Sophism? Proceedings of IRMA conference "Challenges of Information Technology Management in the $21^{\text {st }}$ Century", Anchorage, Alaska, pp68-71

Bentley J F, Lowry G R and Sandy G A, (1999), Towards The Compleat Information Systems Graduate: A Problem Based Learning Approach, Proc. Of $10^{\text {th }}$ Australasian Conference on Information Systems, Wellington, New Zealand, pp 65-75

Checkland P and Holwell S, (1998), Information, Systems and Information Systems; Making Sense of the Field, Wiley, Chichester, UK

Checkland P and Scholes J, (1999), Soft Systems Methodology in Action, Wiley, Chichester, UK
Flood R L, (1995), Solving problem Solving: A Potent Force for Effective Management, Wiley, Chichester, UK

Hawkins J M, (ed), (1987), The Oxford Reference Dictionary, Oxford Century Press, Oxford, UK

Oxford Reference Dictionary, (1987), Hawkins J M (ed), Guild Publishing, London

Rusk R R, (1957), The Doctrines of the Great Educators, Macmillan, London

Sauer C, (1994), Why Information Systems Fail: A Case Study Approach, Alfred Waller Ltd, Oxfordshire, UK

\section{Biography}

David A Banks is a faculty member of the University of South Australia, School of Accounting and Information Systems, where he teaches E Business, Information Systems Development Methodologies, and Collaboration and E Commerce at Masters level and E Commerce and Information Systems Policy at undergraduate level. His research interests are in the areas of project management, information systems, education, E Business and group support systems. 